Araștırma Makalesi - Gönderim Tarihi: 26 Șubat 2019 - Kabul Tarihi: 25 Mayıs 2019

\title{
Kültürel Süreklilik Bağlamında Türk Halk Kültüründe Mavi/Turkuaz Mavisi ve Nazar Boncuğu
}

\author{
Șebnem Soygüder Baturlar ${ }^{1}$ \\ Levent YAYLAGÜL²
}

\begin{abstract}
Öz
$\mathrm{Bu}$ çalışmada, renklerin sembolik anlamları olduğu bilgisinden yola çıkarak nitel/ tarihsel bir yaklaşımla Türk halk kültüründe turkuaz mavisinin ne anlama geldiği ve Türk kültürünün vazgeçilmez öğelerinden biri olan nazar boncuğunun insanları kötülüklerden, nazarlardan koruduğuna dair inanç, kültürel süreklilik bağlamında incelenmiştir.

Bu çalışmada turkuaz mavisinin sembolik olarak Batı'da ve Türk kültüründe ne anlama geldiği, her alanda Batılılaşma yaşanmaktayken bazı kültürel değerlerde ve inançlarda kültürel sürekliliğin gözle görülür biçimde baskın olduğunu "nazar boncuğu" örneği üzerinden açıklanmaktadır.

Çalışmada nitel/tarihsel bir yaklaşımla kaynak taraması yöntemi kullanılmıştır. Buna göre, Türk İslam geleneğinde Batılılaşma çabaları ve kültürel süreklilik kavramlarının açıklanmasının ardından renk sembolizmi ve 5000 yıllık bir gelenek olan nazar boncuğu inancı gibi birtakım kavramların kültürel anlamda Batıılaşama çabalarına rağmen, kültürel süreklilik kavramına bağlı olarak halk kültürü tarafından nasıl göz önüne serilmiştir.
\end{abstract}

Anahtar Kelimeler: Türk kültürü, mavi, turkuaz mavisi, nazar boncuğu, kültürel süreklilik.

Alıntı: Soygüder, S. Ve Yaylagül, L. Kültürel Süreklilik Bağlamında Türk Halk Kültüründe Mavi/Turkuaz Mavisi ve Nazar Boncuğu Akdeniz Üniversitesi Illetișim Fakültesi Dergisi (AKiL) (31), sayfa no. 665-688 Doi:

1 Doç.Dr. Şebnem Soygüder Baturlar Ege Üniversitesi Illetişim Fakültesi Radyo Tv ve Sinema Bölümü sebnem. soyguder@ege.edu.tr ORCID: 0000-9618-171X

2 Doç. Dr. Levent YAYLAGÜL Akdeniz Üniversitesi İletişim Fakültesi Radyo, Televizyon ve Sinema Bölümü lyaylagul@akdeniz.edu.tr ORCID: 0000-0002-8249-204X 
Blue/Turquoise Blue Color and Evil Eye Bead in the Context of Cultural Continuity in Turkish Folk Culture

\section{Abstract}

Based on the knowledge that colors have symbolic meanings, in this study, the meaning of blue/turquoise blue in Turkish folk culture and the belief that is one of the indispensable elements of Turkish culture, that the evil eye bead protects people from evil eye and evils, will be evaluated in terms of cultural continuity with qualitative / historical approach

In this study, it will be tried to explain what the meaning of blue symbolically in the West and in Turkish culture. While in every field of social life the Turkish culture is changing because of Westernization, which is dominant cultural implementation, some cultural values and beliefs such as evil eye and evil eye beads is visibly preserved owing to the cultural continuity in Turkish culture.

After the explanation of the concepts of Westernization and cultural continuity, some concepts such as color symbolism and the belief of evil eye bead, which is a tradition of 5000 years, have not been changed despite the Westernization of Turkish culture and has been preserved by Turkish folk culture depending on the concept of cultural continuity.

Key Words: Turkish culture, blue, turquoise blue, evil eye bead, cultural continuity

\section{Kuramsal Çerçeve}

$\mathrm{B}$ u incelemede halk kültürünün bir parçası olarak nazar boncuğu ve mavi renginin anlamı incelendiği için incelemenin kuramsal dayanağını kültür kavramı oluşturmaktadır. 1800'lü yıllara kadar Batı dillerinde kültür kelimesi daha çok ürün ekme (Latincesi colore) ve hayvan yetiştirme (çobanlık ve besicilik) (cultivation) ile ilgili bir kavram anlamına gelirken zaman içerisinde kelimenin anlamı genişleyerek insanların yetiştirilmesi ve biçimlendirilmesi de kavramın içine dahil edilmiştir. Bu tanım, insanların eylemlerini ve bu eylemler sonucunda ürettikleri maddi ve düşünsel ürünleri kapsar (Güvenç, 1991:95). Kültür kavramı karmaşıktır ve üzerinde herkesin uzlaşabileceği bir anlamı mevcut değildir. Kelimenin anlamı daha çok bu kelimeyi kullanan kişinin siyasal eğilimlerine, dünya görüşüne ve kullanılan bağlama göre değişmektedir (Kartarı, 2001:13). Daha çok antropoloji alanında kabul gören bu anlayışa göre insanların yaptığı ve ürettiği her şey kültüreldir. 19. yüzyılda medeniyetin en gelişkin ürünleri kültür olarak anlaşılmıştır. Anlamın en geniş hali "belirli bir halkın bütün bir yaşam biçimi” olacak şekilde genişlemiştir (Williams, 1993:9).

Doğanın karşısında insanın ürettiği her şey kültürdür. Levi-Strauss doğa ve kültür arasında ayrım yapar. Clifford Geertz ise kültürü insanlar tarafından biçimlendirilen 
anlam ağları yani insan yaşamının düşünsel ve anlamsal boyutu olarak ele almıştır. Batılılar kendi kültürlerini idealize ederken başka kültürleri yabancı ya da öteki olarak görürler ve gösterirler. Bu yönüyle kültür belirli bir topluma özgüdür ve özü itibariyle insanın biyolojik intiyaçlarına dayanır. İnsan tarafından intiyaçlarını karşılamak için geliştirilen kültür, yeni ihtiyaçlar yaratır. Bu süreç devam edip gider (Malinowski, 1990:179).

Bu yaklaşıma göre kültür, yaşam biçimi olarak, o toplumun kültürel kimliğidir. Bir toplum, kültürü aracılığıyla kendi kimliğini de ortaya koyar. Kültür insanın doğaya gösterdiği bir tepkidir. İnsanlar her zaman toplu halde yaşarlar. Bu durum aralarında bir işbirliği ve işbölümüne neden olmuştur. İşbirliği ve iş bölümünün sonucunda insanlar maddi ve manevi üretimde bulunurlar. Maddi üretim daha çok teknoloji ile ilişkili iken, manevi üretim daha çok ideolojinin alanına giren fikir ve düşüncelerin üretimini kapsamaktadır (Sunyer ve Salzman, 1978:57). İnsan ancak teknoloji aracılığıyla doğayla mücadele edebilir ve ona egemen olabilir. Teknoloji en genel tanımıyla, uygulamalı amaçların gerçekleştirilmesi için toplumsal açıdan örgütlenmiş bilgidir. Zamanla işbölümü geliştikçe toplum sosyal sınıflara bölünmüş ve teknoloji ve düşünce (ideoloji) alanı egemen sınıfların denetimine girmiştir. İnsanların sosyal sınıflarla olan bağlantısını genel anlamda üretim araçlarını da kapsayan teknoloji ile kurdukları ilişki belirler. Teknolojiyi ve üretim araç gereçleri ile hammaddeleri kontrol edenler egemen sınıfın üyelerini oluştururken, bunlardan mahrum olanlar ise bağımlı sosyal sınıfların üyeleridirler (Kongar, 1995:343; Spengler, 1973:11).

Kültür evrimsel bir şekilde değişir. 19.yüzyılda Darwin'in evrimci anlayışının kültürel süreçlere uygulanmasıyla kültür, evrimsel bir süreç olarak anlaşılmıştır. Lewis Henry Morgan da kültürleri Vahşi-Barbar-Uygar şeklinde sıralayarak evrimci bir anlayışı dile getirir. Teknoloji, ekonomi, siyasal, düşünsel ve artistik yapıdaki her gelişme birbirini etkiler ve dönüştürür (Kottak, 2002:46). Kültürün temeli sosyo-ekonomiktir. Bu yönüyle kültür insanların maddi ve manevi her türlü etkinliklerini kapsar. Sınıfı toplumlarda kültürün maddi boyutu egemenlerin çıkarına hizmet ederken, manevi boyutu, bu durumu meşrulaştıran bir ideolojiye dönüşür. Düşünsel, manevi üretimde bulunanlarla egemenler arasında bir çıkar ilişkisi vardır. Bu yönüyle kültür, yaşanan üretim ilişkilerinin maddi ve düşünsel ürünleridir, mülkiyet, güç ve iktidar ilişkilerinden bağımsız değildir (Mejuyev, 1998:80).

Buna göre kültür, bütün bir yaşam biçimidir. Bu yaşam biçimi içerisinde üretilen maddi ve düşünsel mallar ve anlamları kapsar. Birbirleriyle yarışan değerler dizgesini içerir ve kesişen anlam haritalarını oluşturur (Barker, 1999:172). Bu genel çerçeveye karşın sosyal bilim literatüründe farklı kültür türleri tanımlanır. En genel anlamıyla ulusal kültür kavramı, herhangi bir ulusu diğerlerinden ayırmak için kullanılır. Bu durum, o ulusu oluşturan sınıflar, etnik, dinsel ve cinsel grupları tek bir potada eritmeye yarayan milliyetçi bir tanımlamadır (Kongar, 1997:31). Bu ayrımlardan ilki üst/yüksek, alt/aşağı kültür ayrımıdır. Toplumu oluşturan farklı sosyal sınıfların toplumsal konumlarına göre bu ayrım yapılmaktadır. 19. yüzyılın ortalarından itibaren kullanılan kavram, sınıfsal olarak seçkinlerin kültürü ile aşağı kültür arasında ayrım yapar. Buradaki ayrım estetik 
açıdan ciddi bağımsız olarak üretilen gerçek sanat ile kitleler için üretilen ticari açıdan kâr beklentisiyle üretilen ürünler arasındaki farkı vurgulaması açısından işlevseldir (Güvenç, 1985:13).

Burada belirtilmesi gereken nokta, kapitalizm öncesi geleneksel halk kültürünün kapitalizmle birlikte bir değişim ve dönüşüm geçirmesidir. Halk kültürü ile popüler kültür kavramsal olarak bir örtüşmeye tekabül ediyormuş gibi görünmesine rağmen ikisi birbirinden farklıdır. Halk kültürü ticari olarak satılmak için emtia formunda üretilmez. Yani halk kültürünü üretmenin amacı ticarî değildir. Kapitalizmle birlikte kültür de endüstrileşmiş ve ticarileşmiştir. Halk kültürü belirli bir ulusa ait olsa da halk kültürü ile ulusal kültür de özdeş değildir. Halk kültürü sadece o sosyal dokuya biçimini veren ulusu hatırlatır. Halk kültürü, halkın organik yaşamından çıkar. Bu halka mensup olmayan başka toplulukların tüketimi için üretilip dağıtılmaz. Halk kültürü gelenekleri, görenekleri, sanatı, halk oyunlarını, hikâyeleri, kılık kıyafeti, takıları, vb. kapsar ve topluluk içinde kuşaktan kuşağa aktarılır. Halk kültürü, popüler kültürden farklıdır ancak popüler kültür sıklıkla halk kültürünün unsurlarını kullanır. Bu açıdan popüler kültür, kapitalizmin ortaya çıkması ile birlikte halk kültürünün piyasada satılmak için emtialaştırılmasıdır. Halk kültürü kâr arayışı olmadan ortaya çıkar. Bazı halk gelenekleri kullanılarak kâr edilse de kâr elde etme amacı halk kültürünün varlık nedeni değildir. Halk, sosyal süreçte kurulan ilişkiler, yaratılan değerler açısından kitle toplumundan farklıdır (Modelski, 1986:4).

Halk tarafından üretilen kültürden halk için endüstriyel olarak üretilen kültüre geçiş kapitalizm ve özellikle sanayi devrimi ile gerçekleşmiştir. Böylece halk kültürünün yerini kitle kültürü almaya başlar. Kitle kültürü, kültür endüstrileri tarafından kitlesel olarak üretilen, dağıtılan ve tüketilen bir kültürdür. Bu kültürel ürünlerden geniş kitleler tarafından beğenilen ve yaygınlaşanlar ise popüler kültürü oluşturur. Popüler kültürün pek çok tanımı vardır. Popüler kültür geniş kitleler tarafından bilinen ve paylaşılan sistemler ve ürünlerdir. Popüler kavramı halk (people) kavramından gelir. Fakat popüler olan ticari koşullar altında üretilir, dağıtılır ve tüketilir. Bu yönüyle popüler kültür, halk kültürünün kültür endüstrileri tarafından emtialaştırılmış halidir. Popüler kültür, kapitalist sosyal sistem içerisinde dolaşıma sokulan ve böylece popüler anlam, haz ve beğenilerin yaratıldığı dinamik bir süreçtir. Burada kültür endüstrileşmiştir, emtia formunda üretilir, satıır ve satın alınarak tüketilir. Popüler kültür, kültür endüstrileri tarafından üretilir (Mutlu, 2001:21).

Kültür endüstrileri, kitlesel tüketim amacıyla kâr elde etmek için kültürel ürünler üreten şirketlerdir. Bu tip endüstriler, gazete, sinema filmi, televizyon programları, kitap ve müzik üreten şirketleri içerir. Theodor Adorno ve Max Horkheimer 1940’ı yıllarda yazdıkları The Culture Industry: Enlightenment of Mass Deception başlıklı çalışmayla bu kavramı popüler hale getirmişlerdir. Adorno ve Horkheimer bu çalışmada tek biçimli ve yıkıcı Amerikan kitle kültürünü eleştirirler. Buna göre, popüler kültür her yerdedir. Gazetede, televizyonda, sinemada, radyoda, sosyal yaşamın her alanı popüler kültür ürünleriyle kaplanmıştır. Popüler kültürün amacı, kitlesel olarak üretilen malların satışı için formüller geliştirmektir. Bu açıdan bütün kültürel ürünler kapitalist toplumlarda 
standartlaşır. Seri üretime dayanan bu ürünler ciddi sanat eserlerine karşı gayriciddi kitle kültürü ürünleridir. Burada sanat da sermaye birikiminin mantığına uyar. Üretim sürecine sanatçılar değil, kâr peşinde koşan kapitalistler karar verirler (Erdoğan, 2001:78).

Kültür endüstrileri, kültürel mallar ve hizmetler üreten endüstrilerdir. Amaçları ticari bir etkinlikte bulunmak ve para kazanmaktır. Burada malların kitlesel olarak üretimi, dağıtımı ve tüketimi esastır. Bu yönüyle kitle kültürüne dayanır. Bu alanda, büyük ölçekli sermaye yatırımı ile işbirliği ve işbölümü içerisinde, teknoloji destekli üretim yapılır. İçerik olarak eğlenceye dayanır. Özünde ekonomik bir etkinlik olmasına rağmen, sadece ekonominin kavram ve araçları ile açıklanamayacak genişlikte kültürel, ideolojik, sosyal, psikolojik boyutları olan ve kapitalizmin ekonomik ve ideolojik olarak yeniden üretilmesini sağlayan etkinliklerdir. Burada, değişim değeri, kullanım değerinin önüne geçer. Yani gerçekte intiyaç olmayan mal ve hizmetler, ticari kaygılarla, ihtiyaç haline getirilir. Estetik kaygıların olmadığı bu etkinlikte ürünlerin içerikleri kitleler açısından avutucu ve ideolojiktir. Kitlelere zevk ve haz vermek amaçlanır. Özü itibariyle irrasyoneldir. İnsanların arzu ve hazları kültür endüstrileri tarafından yaratılır ve yönlendirilir. Üretim süreci ise tamamen yabancılaşmış emeğe ve emeğin sömürüsüne dayanır. Endüstriyel üretim, popüler kültürü halk kültüründen ayıran temel ölçüttür. Kapitalist toplumlarda entelektüellerin kültürünün dışındaki kültür, çoğunluğu çalışan sınıfların tüketimi için üretilir (Erdoğan, 2002:136).

Popüler kültürün toplumsal bir işlevi vardır. Popüler kültür aracılığıyla kitlelerin toplumsal kaygıları giderilir. Toplum için rol modeli oluşturulur. Pek çok toplumsal ilgiye hitap eder. Kültürel emtiaların etkisi her zaman aynıdır. Popüler kültür, kâr amacıyla tüketicilerin arzularının yönlendirilmesine hizmet eder. Frankfurt Okulu üyeleri kapitalist toplumlardaki kültürel tüketimi psikoanalitik olarak analiz edilmesi gereken patolojik bir durum olarak görürler. Reklam endüstrisi kitleleri kontrol eder ve yönlendirir. Bu endüstri, intiyaç için mallar üretmek yerine, ürettiği mallar için kitlelerde intiyaç yaratır. Tüketicileri kontrol eder, disiplin altına alır, eğlendirir ve haz verir. Bu yönüyle kapitalist toplumlarda eğlence, toplumsal yeniden üretim için çok önemlidir. Bunun için Frankfurt Okulu üyeleri müzik, film, radyo, dergiler gibi eğlence kültürü üzerinde odaklanır ${ }^{3}$ (Bkz. Adorno, 2003; Storey, 2000:137).

Halk kültürü, yukarıda da belirtildiği gibi, sanayi öncesi, pazar mekanizması öncesi, emtialaşma öncesi toplulukların kültürüdür. Örneğin sözlü kültür, şarkıların ya da masalların kuşaktan kuşağa sözel olarak aktarılması, halk kültürüne özgüdür. Burada estetik anlayışın oluşmasında geleneklerin egemenliği söz konusudur. Kültür, doğayla daha çok bütünleşir. İnsan bedeni ve zihni, ritüeller aracılığıyla ifade edilir. Semboller kolektif olarak geliştirilir. Halk terimi, ideolojik bir inşadır ve modern toplumların eleştirisini içerir. Halk kültürü milliyetçi ideolojinin dayanaklarından birisini oluşturur. Bir ulusun gerçek ruhunun (inançlar, değerler, kılık kıyafet, müzik, hikâyeler, yiyecekler, müzik, halk dansları, şarkıları ulusal kimlik) ifadesini halk kültüründe bulduğu düşünülür.

3 Almanya'da faşizm kitleleri harekete geçirmek için bilince yönelik sembolleri ve stilleri içeren eğlence malzemelerinden faydalanmıştır. 
Bu yönüyle halk kültürü ticari (ayartıcı/baştan çıkarıcı) kültürün karşıtıdır. Halk kültürü küresel kapitalist tüketim kültürünün karşısında yerel ve egzotik olanı temsil eder (Oktay, 1997:21).

Kültürler ve gelenekler, özellikle halk kültürü, modernleşme ile değişime uğrar. Kültüre ilişkin kategoriler bu süreçte anlamsal olarak farklılaşır. Kültürel değişim çelişkileri de beraberinde getirir. Her kültürün geçmişini oluşturan bir geleneksel boyutu vardır. Geçmiş, gelenek ve değerlere dayanır. Modernleşme aynı zamanda bir kültürel değişmedir. 15. yüzyılda burjuvazinin toplumsal bir güç olarak tarih sahnesine çıkması ve aristokrasi ile mücadele etmesi Rönesans, Reform, Aydınlanma, Sanayi Devrimi ve Fransız İhtilali ile somutlaşmıştır. Bu aynı zamanda kültürel ve düşünsel bir dönüşümü de beraberinde getirir. Her kültürün kimliği, o toplumun geleneklerine ve toplumsal deneyimlerine dayanır. Gelenekler aynı zamanda geleceğe yönelik bir bakış da sunar. $\mathrm{Bu}$ yönüyle kültür durağan, soyut ve manevi değil, somuttur. Tarihsel kategorileri Aydınlanma sürecinde eleştiri süzgecinden geçiren burjuvazi, gelenekleri tarihsel ve toplumsal gelişmelere göre yeniden yapılandırmış ve yorumlamıştır. İnsanlar kültürlerini hem saklar ve korur hem de değiştirirler. Gelenekler de sabit değil, değişkendir ve değiştirilerek kuşaktan kuşağa aktarılır. Böylece, geleneksel unsurların tarihsel süreç içerisinde elde edilen kültürel mirasın kuşaktan kuşağa aktarılmasıyla kültürel kimlikler inşa edilir (Petkovic, 2007:23).

Ancak geleneğe saygı duyulması, geleneğin eleştirel olmayan bir şekilde irrasyonel olarak ya da mekanik bir şekilde kabul edilmesi anlamına gelmez. Kültürün içeriği maddi gelişmelere bağlı olarak değişir. Geçmişte ortaya çıkmış geleneksel unsurlar, çağdaş gelişimin gerekliliği olarak yeniden değerlendirilir. Modernleşme sürecinde geleneksel değerler ve kültür yeniden şekillendirilmiştir. Geçmişin mitleri, önyargıları, ideolojileri, değerleri, anlayış ve toplumsal davranış kalıpları değişmektedir. Kültürde durgunluk, gerileme ve gelenekselleşmenin yanında değişim de vardır. Modernleşme, toplumların ekonomik, siyasal, sosyal ve kültürel alanlarını değiştirmiştir. Modernleşme bu alanları yeniden yorumlar ve farklılaştırır. Özellikle ilerlemeyi engelleyen değerler dönüştürülerek yaşamı kolaylaştıran modern yorumlarla laik-bilimsel bir kültür ikame edilmektedir. Modernleşme geleneksel kültürün radikal bir şekilde dönüşmesine neden olmuştur. Dinin egemenliği yerini laikliğe bırakırken, milliyetçi ideoloji sayesinde milli kültür de milli egemenliğin kaynağı haline getirilir (Giddens, 1990:166). ${ }^{4}$

Modernleşmenin bilimsel ayağı olan Sanayi Devrimi 18. yüzyılın sonlarında İngiltere'de eğirme makinelerinin ortaya çıkmasıyla başlamıştır. Batı dışı ülkeler ise modernleşmeyi Batılılaşma olarak deneyimlemişlerdir. Modernleşme, Batı kültürünü

\footnotetext{
4 Gramsci ve Althusser gibi "Marksist" düşünürler popüler kültürü ideolojik bir hegemonya aracı olarak görürler. Bu kavram kapitalizm gibi sınıflı toplumlarda egemen grupların kendi egemenliklerini alt grupların üzerindeki hakîmiyetlerini nasıl sağladıklarını anlamak için kullanılır. Hegemonya kavramı ideoloji kavramını da içine alacak şekilde insanların düşünme ve hissetme biçimlerini egemen sınıfın egemenliklerini sürdürmede önemli unsurlar olarak görülür. Hegemonya aracılığıyla insanlarda sağduyu denilen, dünya hakkında belirli duyarlılıklar yaratılarak toplum bir bütünlük içerisinde bir arada tutulur (O'Shaughnessy, 1995:89). Önce Althuser'in daha sonra da Gramsci'nin temel görüşlerinden hareket eden İngiliz Kültürel İncelemeler geleneği kültür kavramını daha çok gelenekler ilgilenen antropolojik/etnolojik anlamından uzaklaştırarak kavramı egemen ideoloji anlamına gelecek şekilde siyasal bir anlam yüklemiştir (Korkmaz, 2008:179).
} 
kabul etmek ve gündelik yaşamı buna göre düzenlemek anlamına gelir. Böylece Batılaşma, geleneksel değerlere dayanan (örn., Türkiye gibi) Doğulu toplumların kendi geleneksel kültürel unsurlarını Batılı unsurlarla değiştirmesidir. Bu açıdan modernleşme, geleneksel kültürü dönüştürür. Modernleşen ülkeler, özellikle Batı'nın tüketim mallarının ve kalıplarının benimsetilmesi yoluyla Batı'nın pazarı haline getirilir. Doğulu toplumlar, Batı'nın teknolojik ürünlerini, bürokratik yapısını, yaşam tarzlarını, düşünme ve davranış biçimlerini ve dünya görüşlerini benimseyerek geleneksel kültürün dönüşmesine neden olur. Ancak bu dönüşüm düz bir süreç değildir; bu gelişmeler, toplumsal açıdan gerginlik ve sürtüşmelere neden olurlar. Modernleşme, kentleşme (köyden kente göç), okuryazarlığın, maddi tüketimin ve toplumsal etkileşimin artışı, laikliğin yaygınlaşması, kitle iletişimin ve bürokrasinin ve merkezi yönetimin gelişmesi anlamına gelir. Modernleşme ile daha çok teknolojik gelişme yaşanmış ve kapitalist ekonomi kurumsallaşmıştır. Bu maddi değişimlere paralel olarak kültürel değerler olarak akılıılık, milliyetçilik, ilerleme, gelişme, laiklik ve çalışmanın önemine yapılan vurgu gelmektedir (Galland ve Lemel, 2008:153).

1950'live 60'lı yıllarda modernleşme, Talcot Parsonsve Daniel Lernergibidüşün adamları tarafından geleneksel olanın karşıtı anlamında modern kavramını kullanmışlardır. Batılı toplumlar, modern toplumlar kategorisine girerken modernleşme kuramları ile geleneksel toplumların geleneksel kültürlerini terk ederek modernleşebilecekleri düşünülmüştür. Bu yaklaşım kültürü evrimci bir şekilde ele alır. Çünkü modernleşme bir toplumun kademeli olarak gelenekselden moderne doğru geçişini öngörür. Ancak kültürel ve sosyal değişim bu kadar kolay ve tek boyutlu değildir. Modernizasyon bir değişim süreci olarak toplumu, ekonominin yanı sıra kültürel açıdan da dönüştürür. Batı ülkelerinin kendi içsel gelişmelerinin sonucu olarak yaşadıkları modernleşme dış zorlama ile geleneksel toplumlara uygulanır. Böylece geleneğin üstesinden gelinebileceği düşünülür. Modernizm geleneksel yolların terk edilmesini öngörür. Ekonomik (tarımdan sanayiye) ve siyasal (monarşiden demokrasiye) değişmelere rağmen, geleneksel değerlerin büyük bir kısmı toplumun bilincinde ve pratiklerinde varlığını sürdürmeye devam eder. Özellikle geleneksel kültürün geçmişte kökleşmiş kadercilik boyutu kolayca değişmez. ${ }^{5}$ Bu yaklaşımda modern bilime önem verilmez. $\mathrm{Bu}$ yönüyle geleneksel değerler, laik/bilimsel değerlere karşıtlık oluşturur. Geleneksel toplumlarda din çok önemlidir. Aile, otorite, gelenekler, boşanmanın olmaması, kadının ikincil konumda olmasına karşılık laik bilimsel endüstriyel toplumlarda zenginlik, bireyselleşme, maddi değerlerin ön plana çıkması, ilerleme, aydınlanma, kentlileşen orta üst sınıflara mensup kadınların özgürleşmesi, kamusal alana çıkış, eğitimden faydalanma ve farklı olana saygı esastır (Inglehart ve Barker, 2000:19).

Türk kültürünün tarihsel gelişimine kısaca bakıldığında bunlar arasında İslam öncesi Türk toplumunun göçebe yaşayışından kaynaklanan uygulamalar, İslâmiyet'in

\footnotetext{
5 Özellikle SSCB'nin dağılmasından sonra, postmodern kültür kuramı ve Huntington tarafından geliştirilen "medeniyetler çatışması" tezi, kültürel sürekliliğe vurgu yapar. Burada modernizme özgü kategorilerin Batılı toplumlara özgü olduğu ve Doğulu toplumlar tarafından taklit edilemeyeceği belirtilir. SSCB'nin yıkılmasından sonraki çatışmaların modern Batı (Hristiyan) ve geleneksel Doğu (İslam ve Budizm) arasında gerçekleşeceğini düşünür. Özellikle postmodern kültür kuramı ile modernleşme yerini geleneksel değerlere geri dönüşe bırakmıştır (Huntington, 2008: 267).
} 
kabul edilmesiyle başta Arap ve Acemlerin etkisi ve üçüncüsü de Tanzimat’tan beri sürmekte olan modernleşme ve Batılılaşma çabalarının bir parçası olarak Yunan, Roma ve Aydınlanma sonrası süreci kapsayan Avrupa kültürü ile etkileşim gelmektedir (Akşin,1997:288). Osmanlı Devleti 18. yüzyıldan itibaren gerileme ve çöküşten kurtuluşun çaresi olarak Batılılaşmayı görmüştür. Bunun için reformlar yapmıştır. Reformlar daha çok askeri ve askeri eğitim (askeri tıbbiye ve askeri mühendislik) alanıyla sınırlandırımıştır (Aktar, 1993). Bu değişikliklerle Batı medeniyeti dış görünüşü itibariyle taklit edilmeye çalışılmıştır. Batının teknik ürünleri, yaşam tarzı, yöntem ve ilkeleri, tüketim kalıpları kılık kıyafet ve dış görünüş gibi unsurlar ve ölçü birimleri özellikle Cumhuriyet Dönemi'nde yoğun bir şekilde kabul görmüştür. Sosyal yaşam, kamu hizmetleri, kurumsal yapı ve bürokrasi Batıdaki gibi düzenlenmeye çalışılmıştır. Ancak Osmanlı-Türk modernleşmesi Batının sadece görüntüsünü ya da dış görünüşünü taklit etmiş fakat değişmesi gereken toplumsal zihniyetin kendisi tamamen modern bir yönde değişememiştir. Ortaya modern ile geleneksel arasında melez bir zihinsel yapı ve yaralı bir bilinç çıkmıştır. Bir yanıyla Batının modern teknolojik ürünlerini kullanan, bir yandan da nazar inancı gibi geleneksel değerlerin sürdürüldüğü çelişkili bir yapı ortaya çıkmıştır. Yani Batıda ortaçağa karşı verilen mücadelelerle Rönesans, Reform ve Aydınlanma sürecinde Batılı toplumların kültürü ve zihin yapıları da dönüşmüştür. Batıda ekonomik yapı (kapitalistleşme, sanayi devrimi) ve zihinsel yapı (Rönesans, Reform, Aydınlanma, Fransız İhtilali, laiklik, milliyetçilik) karşılıklı olarak birbirini etkileyerek dönüşmüştür. Osmanlı Türk toplumu böyle bir değişim süreci geçirmemiştir. Batılaşma çabasına halk Frenkleşme (İslam dininden uzaklaşma) olarak bakmış ve tepki göstermiştir. Oysa kültür ve zihniyet bir nesne ya da eşya gibi alınıp ona sahip olunamaz (Berkes, 1975:196). Doğu ile Batının kültürü, zihniyeti, iş yapış biçimi, hayatı anlama ve anlamlandırma biçimleri birbirinden farklıdır. Doğu gelenekselliği aşamamıştır (Tanpınar, 1996:27). Bunun tarihsel nedenleri vardır. Özellikle Batıda gelişen milliyetçiliğin Balkanlarda hızla yayılması ve Hristiyanların Osmanlılara karşı ayaklanmaları sonucu Osmanlılar kendilerini daha çok İslam dini (ve kültürü) üzerinden tanımlamaya başlamışlardır. Hatta daha sonra gelişen Türk milliyetçiliğinde bile Sünni İslam Türk kimliğinin kurucu unsuru olmaya devam etmiştir. Cumhuriyetin düşünsel açıdan kurucu babalarından birisi olan Ziya Gökalp bile yaşanan değişimi Türkleşmek, İslamlaşmak ve Muasırlaşmak olarak tanımlamıştır. Bu süreçte birbiriyle çelişen/çatışan üç unsur pragmatik bir şekilde yan yana getirilmiştir (Kuyaş, 2016:26). Ziya Gökalp, kültürü medeniyet ve hars olarak ayırmış, medeniyeti kültürün maddi boyutu harsı ise manevi ve düşünsel boyutu olarak kodlamıştır. Böylece Batı kültürünün maddi ve teknik boyutunun alınabileceğini, buna karşın düşünsel ve maddi boyutunun alınmaması gerektiğini vurgulamıştır. Batılılaşma konusundaki bu anlayışın sonucunda (bütün diğer tarihsel ve toplumsal nedenler baki kalmak kaydıyla) bilinç düzeyinde geleneksel ümmet toplumundan çağdaş ulus toplumuna geçilememiştir. Bu durum düşünce ve kültür dünyasında tutarsızlıklara neden olmuştur. Bir yandan Batı'ya özgü teknik ve maddi ürünler, öbür yanda geleneksel kültür ve değerler bir arada yaşamaya zorlanmışıır (Berkes, 2006:423). Gökalp burada birbirileriyle uzlaşmayacak, çelişik üç kültürel durumu sentezlemeye çalışırken bile aslında kültürel kopuştan ziyade kültürel sürekliliğe vurgu yapmaktadır. Türkleşmenin yanına İslamlaşmanın konması Türk Kültüründe İslam etkisinin devam edeceği yönündeki kültürel süreklilik 
anlayışının bir dışavurumudur.

Renkler, kültürün en önemli parçalarındandır. İnsanların yeryüzünde var oldukları tarihlerden günümüze birbirilerini ve doğayı bilimsel, düşünsel, sanatsal olarak okumaları renk kodlarıyla mümkün olmuştur. Her rengin bireysel, kültürel ve evrensel olarak anlamları vardır.

Bütün renklerin anlamı tarihsel ve kültüreldir. Toplumlara, kültürlere ve tarihsel/ toplumsal gelişmelere göre renklere yüklenen anlamlar farklılaşabilir. Gerçekten renk, tarihçi için -sosyolog ya da antropolog için olduğu gibi- öncelikle toplumsal bir olgu olarak tanımlanır. Rengi oluşturan ona tanımını ve anlamını veren, kodlarını ve değerlerini meydana getiren, pratiklerini düzenleyen ve önemini belirleyen toplumdur. Renk sorunları, öncelikle ve her zaman toplumsal sorunlardır; çünkü insan yalnız değil, toplum içinde yaşamaktadır (Pastoureau, 2013: 12).

Bu çalışmada öncelikle, mavi rengin Batı ve Türk kültüründe tarihsel süreç içerisinde sembolik olarak ne anlama geldiği açıklanmıştır. Bu arada mavinin tonlarından biri olan ve Batılılar tarafından Türklerin rengi olduğu kabul edilen turkuaz renginin kültürel açıdan önemi de ortaya konulmuştur. Son olarak da 5000 yıllık kültürel bir ürün olan kullandığı mavi nazar boncukları "kültürel süreklilik" kavramı çerçevesinde açıklanmıştır.

\section{Batı Kültüründe Turkuaz Mavisi Rengin Anlamı}

Kültürel semboller ve kodlar olarak kabul edilen renkler, çeşitli bilim insanları tarafından incelenmektedir. Eliade(2018: 22)'e göre, “imgeler, simgeler, mitler psikenin sorumsuz yaratıları değillerdir. Bunlar bir gerçekliğe cevap verirler ve varlığın en gizli özelliklerini ortaya çıkarma işlevini yerine getirirler. Bunların incelenmesi insanı, "kısaca insan"ı tarihin koşullarıyla henüz uyuşmamış olanı anlamamıza imkân tanır. Her tarihsel varlık, tarih öncesindeki insanlığın büyük bir parçasını kendinde taşır. Bu kuşkusuz pozitivizmin en acımasız zamanları da dahil, hiçbir zaman unutulmamış olan bir noktadır".

Michel Pastoureau, Batı kültüründe mavinin renk simgeselciliğinde ne anlama geldiğini anlattığı Mavi: Bir Rengin Tarihi adlı kitabında, mavinin Batı toplumu için Neolitik Çağ'dan XX. yüzyıla kadar değişen anlamlarını ortaya koymaya çalışmıştır. Bu bilginin sadece bir renk bilgisi olarak geçiştirilmeyecek kadar önemli olduğunu, rengin tarih içindeki anlamlarının aslında içinde bulunduğu toplumu da her yönüyle (dinsel, kültürel, toplumsal, sanatsal vb.) yansıttığını söylemek mümkündür.

Batı'da Üst Paleotik Çağ'da mavi ve yeşil renkler yoktur. Birkaç bin yıl sonra, ilk boyama tekniklerinin ortaya çıktığı Neolitik Çağ'da da durum aynıdır. Mavi renk yine yoktur. XIX. yüzyıldaki birçok bilim insanı Antik Çağ'da "insanlar maviyi görebiliyorlar mıydı acaba?" diye bu konuyu sorgulamışlardır. Çünkü filologlar da dilde maviye dair bir 
kelime bulamamışlardır (Pastoureau, 2013: 15-16). Adeta Batılıların maviyi görmezden geldikleri düşünülebilir. Bir başka görüşe göre, Batıda genellikle gökyüzü sisli, puslu, yağmurlu ve karanlıktır. Buna karşın güneş, Doğuya cömert davranmış, pırıl pırıl mavi yüzünü hep göstermiştir. Dolayısıyla Doğu maviyi her tür kültürel, sanatsal ve dinsel üretiminde kullanmıştır. Rengin psikolojik anlamlarına bakıldığında renge atfedilen anlamlar hep insanlarda yarattığı duygusal etkiye göre biçimlenmiştir.

Yunanlılar ve sonrasında ise Romalılar maviyi barbarlıkla özdeşleştirdikleri için çok az kullanmışlardır. Işığı mavi ile değil, sarı veya beyaz ile sembolize etmişlerdir. Romalılar, XIX. yüzyıldaki kimi uzmanların sandığı gibi "mavi körü" değildiyse de maviye en iyi intimalle ilgisiz, en kötü ihtimalle düşmandılar. Gerçekte mavi onlara göre özellikle Caesar'ın ve Tacitus'un söylediklerine bakılırsa, düşmanlarını korkutmak için bedenlerini bu renge boyama alışkanlığı olan barbarların; Keltlerin ve Germenlerin rengidir. Romalılarda mavi, kişiyi küçülten, garip karşılanan bir renktir ve yasın işaretidir. Ölümle ve ölümden sonra gidilen yerle ilişkilendirilmiştir. Mavi gözler fiziksel çirkinliğin göstergesiydi. Mavi gözlü kadınlar, iffetsiz; mavi gözlü erkeklerse ya kadınsı ya da barbar olarak nitelendirilmekteydi (Pastoureau, 2013: 29-30).

Toplumların renklere verdiği değerler kullanımlarıyla, boyar maddelerini kolay elde edip etmemeleri ile yakından ilişkilidir. Kısacası sebep .ekonomiktir. Örneğin, mor ve kırmızı, tarih boyunca Batı tarafından çok zor elde edilen, boyar maddesi Avrupa'da olmayan renklerdi. Sözgelimi moru Yakın Doğu'dan, kırmızıyı Güney Amerika'dan ve Asya'dan ithal etmek zorundaydılar. Ekonomik olarak çok pahalıydılar ve bu nedenle de söz konusu bu iki renk tarih boyunca asaletin sembolü durumuna gelmişlerdir. Bu renkler, kurutulmuş mineraller halinde Doğu'dan ithal edildiğinden pahalı ve değerlidir, dolayısıyla, sadece toplumun yönetici aristokrat sınıfın, komutanların veya din adamlarının bu renkleri kullanmasına izin verilirdi. Aynı şey mavi için de geçerlidir. Fakat tek farkla; o da diğerleri gibi boyar maddesi az bulunan mavi rengin Batı'da uzun süre değerli bir renk statüsüne çıkamamış olmasıdır.

Mavinin tarih boyunca temel olarak üç temel boyar hammaddesi bulunmaktadır. Bunlar az da olsa Avrupa'da yetişen çivitotu ve sadece Güney Asya'da Hindistan'da bulunan çivit ağacı (indigo) ve yine Yakın ve Orta Doğu'da (İran ve Afganistan) bulunan lapis taşıdır. Tonları olarak da bakıldığında açık maviler indigo; koyu maviler ise ultramarindir. İleride bahsedileceği gibi ayrıca kobalt madeni ve turkuaz taşı da mavinin farklı tonlarını ortaya çıkaran ve Türk kültüründe önemi yer tutan yeşile çalan mavilerdir.

"İndigo" ve "ultramarin" sözcükleri tarihi olarak rengin yapıldığı malzemeyi değil, geldiği yeri göstermektedir,. Ultramarin İtalyanca "denizler ötesinden", indigo ise Yunancadır ve "Hindistan'dan" demektir (Finlay, 2007: 286). Avrupa'da mavi rengini elde edebilmek için yabani olarak yetişen ve turpgillerden bir bitki olan çivitotunu (Latince: guastrum, vitrum, isatis, waida) boya olarak kullanan Keltler ve Germenlerdir. Mavi rengini veren madde (indigotin) esas olarak yapraklarda bulunur ama mavi rengi elde etmek için gereken işlemler uzun ve karmaşıktır (Pastoureu, 2013:19). 
Finlay de kitabında vücutlarını maviye boyayan toplumlardan söz eder: MÖ 55 yılında Roma İmparatoru Julius Ceasar'a karşı direnen Bretonlar vücutlarını vitrum denen mavi renk ile boyuyorlardı bu rengin çivit olup olmadığı bilinmiyor. Bretonlar neden vücutlarını maviye boyamak istesinler? Romalıları korkutmak için mi, yoksa bu ritüelin başka bir anlamı mı vardı? Savaşçıların çivit otu ile kendilerini boyamalarının en olası sebebi bu otun olağanüstü derecede kanamayı durdurmasıdır. Onu sürmek ve savaş sonrası hazır tutmak ilkel bir çöl hastanesini önceden hazırlamak gibi bir şeydir (Finlay, 2007: 289).

Yine aynı şekilde başka bir kaynakta Roma İmparatoru Cesar'ın, Fransa'nın batısında bulunan Bretegna'da muayyen ayinlere kadınların çıplak vücutlarını maviye boyayarak katıldıklarını anlatmaktadır. Amon-Ra Mısır İlahının da maviye boyanmış bir kişi veya bir koç tarafından temsil edildiği nakledilir (aktaran, Atabek, 1983: 33-46).1980'lerde Manchester yakınındaki Cheshire'da Lidow Turba bataklığında gövdeleri mavi dövmelerle kaplı birçok ceset bulunmuştur. Bilim adamları bu cesetlerin MÖ 300 yılından kalma olduğunu tespit etmişlerdir (Finlay, 2007: 290). Mel Gibson'un yönetmenliğini yaptığı ve başrolünde oynadığı, 1995 ABD yapımı olan Braveheart (Cesur Yürek) adlı filmde Kelt kültürünün mitolojik özelliğini yansıtan mavi boya İskoç savaşçılarının yüz ve vücutlarında görülmektedir. Sinema sanatı da bu kültürel renk bilgisinden yararlanmıştır.

İndigo, sayısız çeşitleri olan, ama hiçbirinin vatanı Avrupa olmayan çivit ağacının yaprağından elde edilirdi. Doğu Hint Adaları'ndaki ve Ortadoğu'daki çivit ağacı, yüksekliği iki metreyi geçmeyen çalılıklar biçimindedir. Çivit ağacının çivitotundan daha güçlü boyar maddesi (indikotin) bulunur. Indigoyla boyama işlemi Hindistan'da Neolitik Çağ'dan beri bilinmektedir. Hindistan için bu rengin boyar maddesi olan indigo, zamanla ihracat ürünü haline gelmiştir (Pastoureau, 2013: 19-20). Çivit ekiminin Hindistan'ın İndus Vadisi'nde beş bin yıl önce başladığı düşünülmektedir. Orada ona “nila” deniyordu. Kısa sürede Kuzey'e, Güney'e, Doğu'ya ve Batı'ya yayıldı. British Museum'da M.Ö. 7. yüzyıla ait tabletlerde Babil'deki boya tarifleri vardır. Bu tabletler çividin Mezopotamya'da 2700 yıl önce kullanıldığını ortaya koymaktadır (Finlay, 2007: 286).

İran ve Afganistan'da ise lapis taşının maden yatakları çoktur ve Batılılar, lapis taşından elde edilen maviyi (ultramarin tonunu) uzun yıllar bu bölgelerden tedarik etmişlerdir (Pastoureau, 2013:23). Finlay ultramarin için, "bana daima okyanus tadı vermiş bir sözcüktür. Akdeniz'in bile güneşli bir sabah yansıtacağından daha mavi bir maviyi akla getiren yumuşak, tuzlu bir sesi var. Ama Ortaçağ italyanları bu en değerli boyaya deniz adı verirken hiç de özel bir deniz rengini anma niyetleri yoktu" der. Oltramarino "denizlerin ötesinden" anlamında teknik bir terimdi ve sadece boyayı değil, aynı zamanda ithal edilen birkaç ürünü de anlatıyordu. Bu özel "oltramarino"nun denizlerin ötesinden geldiği kesindi: Boya, yarı değerli bir taş olan lapis lazuliden yapılıyordu. En önemli maden yatakları Afganistan'daydı (Finlay, 2007: 255). 
sevilmeyen ve istenmeyen bir renkken, Doğu'da en az 5000 yıldır insanlar mavi rengi kolayca elde edebilmekte ve kumaşlarında, halılarında ve her yerde rahatlıkla kullanabilmekteydiler. Dahası Tanrılarını dahi mavi renginde düşlüyorlardı. Mısır Tanrısı Amon-Ra ve aynı şekilde Hint tanrılarından en büyükleri kabul edilen Rama ve Krişna gibi.

Mavi Antik Roma'da olduğu gibi Erken Ortaçağ Avrupası'nda da değer görmemiştir. Mavi hiçbir şey ifade etmez ya da çok az şey ifade eder. Gökyüzünün rengi bile kabul edilmez. Gökyüzünü bile kırmızı, beyaz ve altın sarısı temsil etmekteydi. Bu dönemde mavi, sarayda ve soylular arasında hiç kullanılmayan bir renk iken, köylüler ve aşağı tabakadan kişiler mavi giysiler giyinmektedir. XII. yüzyılın ikinci yarısına kadar bu böyle sürecektir. Batı'da XII. yüzyılın ikinci yarısından sonra mavi, en sevilen renk ve hatta aristokrasinin rengi olmuştur. Artık, "mavi”nin devri başlar. Kiliselere mavi camlı vitraylar yapılır. O artık "ışık"ın rengidir. Yavaş yavaş da göklerin, bakire Meryem Ananın ve kralların rengi olmuştur (Pastoureau, 2013: 34-50).

Bakire Meryem'in mantosu veya elbiseleri mavi renginde resmedilmeye başlar. Gerçekte mavi giyinmemiştir. Meryem haçın üzerinde ölen oğlunun yasını tutan bir annedir. Bu düşünce ile mavi artık kiliselerde, Hıristiyan sanatında ortaya çıkmaya başlar. Rengin sembolik anlamı artık "keder" ve "yas"tır. Meryem Ana şüphesiz farklı kültürlerde farklı renklerle resmedilmiştir. Örneğin, Rus ikonlarında kırmızı iken, Bizans ressamları ise onu çoğunlukla morlar içinde gösterir. Bazen beyaz da giyer. Renk simgeselliğiyle ilgili sorun veya belki de ilginç tarafı sabit olmayışıdır. Kırmızı doğum, mor gizem için olabilir, mavi göklerin kraliçesini, beyaz masumiyeti, siyah yası simgeler. Ressamlar Meryem'e renk verirken onun tutkusunun neyi temsil edeceğini değil, ona neyin onur vereceğini düşünmüşler ve bu nedenle, maliyet ve az bulunurluğuna göre bu rengi kararlaştırmışlardır. XV. yüzyıl Hollanda'sında Meryem skarlet giydirilmiş, Bizans'ın seçimi ise mor rengiymiş çünkü çok az insan o rengi giyinebilecek kadar önemliymiş, XIII. yüzyılda ise İtalya'da ultramarin rengi en pahalı renkmiş ve bu yüzden inancın en değerli simgesini bu mavi ile giydirmişler (Finlay, 2007: 265).

XVIII. yüzyılın ikinci yarısından sonra tüm toplumsal sınıflarda en sevilen renk mavi olmuştur. Özellikle Avrupa'da köylüler bu rengi çok sevmiştir. Mavi, XVIII. yüzyılda ilerlemenin, aydınlanmanın, hayallerin ve özgürlüklerin rengi olmuş, Romantizm hareketi ile Amerikan ve Fransız Devrimlerinde sembolik bir ağırlığı olmuştur. 1920 'lerden sonra dünya renklenir. İnsanlar maviye döner. Denizci mavisi dokumalar yaygınlaşır. Siyah olan üniformalar mavi olur. Denizciler, havacılar, polisler, postacılar, itfaiyeciler, kilise adamları giysilerinde maviye geçer. Amerika ve Avrupa'da 1910-1950 arası tüm siyah üniformalar maviye dönüşür (Pastoureau, 2013: 113-114).

Mavi çok yoğun kullanılırsa hüznü çağrıştırır. İngilizcede "I am Blue", "I have the Blues" diye bir söz vardır. Anlamı "dokunma, hüzünlüyüm" demektir. İçlerine döndüklerinde bunu söylerler. Hatta mavi bir başka sanat alanına isim babalığı yapmıştır. Bir caz formu olan "blues" adını mavinin çağrıştırdığı derin anlamdan alır. Amerika'daki zenci toplumun acısını blues dile getirir (Uçar, 2004:55). 1950’lerde Avrupa'da Amerika'dan 
öğrenilen kot pantolonlar (blue Jean) piyasaya çıkar. Mavinin günümüzde popüler olma sebebi ise blue jeanlerdir. Gayri resmi, sınıfsız, cinsiyetsiz, yaş limiti olmayan, kent ya da taşraya uygun kitlelerin en çok talep ettiği giysidir (Fiske, 1991:11-33). Bilindiği gibi kitlelerce çok sayıda ve isteyerek, beğenilerek tüketilmesi o ürünü popüler yapar. Şüphesiz mavi renkli kot pantolonlar günümüzün en önemli popüler kültür ürünleridir.

Günümüzde dünyada hem kadınlar hem de erkekler tarafından en sevilen renk mavidir. Mavi şaşırtmaz, yaralamaz, başkaldırmaz, tedirgin etmez, sakindir, barışçıldır, mesafelidir, neredeyse yansızdır. Düş kurdurur (Novalis'in mavi çiçeği ve blues gibi düşünelim); ama bu melankolik düşünün uyuşturucu bir yanı vardır. Hastane ve çocuk odalarının mavi renk olması hastaları ve çocukları sakinleştirir. Sakinleştirici ilaçların çoğu mavi renktedir. Trafikte izin verilen her şey için mavi renk kullanılır. Mavi saldırmaz, hiçbir şeye karşı koymaz; yatıştııır ve bir araya getirir. Büyük uluslararası örgütler de amblem ve logolarında bu rengi kullanır (BM Birleşmiş Milletler; UNESCO; Avrupa Konseyi, Avrupa Birliği vb.). Mavi, halklar arasındaki barışı ve uzlaşmayı sağlamakla yükümlü uluslararası bir renk halini almıştır. Örneğin, Birleşmiş Milletler'in mavi bereli askerleri gibi (Pastoureau, 2013: 164-165).

Renk sembolizmi, kendini özellikle soyut sanatta göstermektedir. Soyut sanatta biçimler kaybolur. Sanatçının kullandığı her rengin bir anlamı vardır. Modern sanatın babası da kabul edilen ve Bau Haus'un resim hocalarından olan Rus ressam Vassily Kandsky'e göre; Soyutlama nesneyi tinsel gözle görmektir. Nesnenin tinsel gözle görülmesi, nesnenin içinde saklı olanı çözmektir, özü sezmektir. Nesnenin içindeki özü seçmekse gerçekliği sezmektir. Kandinsky bu görüşünü tuvale taşırken renklere başvurur. Görünüş ile öz arasındaki ilişkiyi bu şekilde sorgular. Soyut imge, görünenden farklı bir gerçeklik değerinin göstergesi olunca soyutlama bağlamında kullanılan renklere de farklı anlamlar yüklenir. Rengin tinsel bir gücü olduğunu ve izleyicide tinsel bir titreşim uyandırdığını düşünen Kandinsky için kırmızı insani olanı, bedensel olanı; mavi ise ruhani ve göksel olanı simgeler (Öndin, 2008, 105).

Mavi derinleşmeye eğilimli bir renktir. Yoğunlaştıkça, özellikle koyu tonlarıyla daha da içsel bir etki yaratır, koyulaştıkça izleyiciyi, sonsuzluğa davet eder ve böylece pürlüğe olduğu kadar hisleri kavranmaya da çekmiş olur. Mavi, gök (Himmel) rengidir. "Gök" sözcüğü maviyi çağrıştırır (Kandinsky, 2017:56).

Hale, kutsal kişiler için sarıyken, tinsel varlıklar için gök mavisidir. Mavi derinlikli bir dinginlik öğesi de ortaya koyar. Siyaha yaklaştıkça yas ile ilgili bir hal alır. Sonu olmayan şeylere karşı bir derinleşme sağlar (Kandsky, 2017: 56-57). Mavi renk, şiddet yanlısı değildir. Mavide insanı serinleten bir etki vardır (Kandinsky, 2017: 57). Psikolojik anlamda renkleri adlandıran teorisyenler Goethe'den Johannes İtten'e ve önemli bir başka modern resim sanatçısı Piet Modrian'a kadar neredeyse tüm sanatçılar için mavi karanlığı, hüznü ve içselliği anlatmaktadır.

Turkuaz rengi ise Batı kültürünün Türk kültürüne atfettiği yeşile çalan bir mavi tonudur. 


\section{Türk Kültüründe Turkuaz Mavisi Rengin Anlamı}

Türkçede yer alan 18 renk ismi tamamen Arapçadır. "Mavi" de Arapça bir kelimedir (Adalar Subaşı, 2012: 967). "ma-i"den gelir, Arapçada anlamı "su rengi" demektir. Turkuaz, firuze rengi ve kobalt mavisi ise "Türk mavisi" olarak adlandırılır. Bu, yeşile çalan açık bir mavidir (Eminoğlu, 2014: 450). Turkuaz ve firuze aynı zamanda yeşile bakan mavi bir taştır. Renge bu ismi "turqoise" olarak Fransızlar vermiştir. Fakat sonrasında tüm Batı dünyası bu mavi tonuna "turkuaz" demiştir.

Türkçede bu rengin üç çeşit söylenişi vardır: Turkuaz, türkuaz veya turkuvaz. Hatice Eminoğlu (2012:445) da Türkçe'de Renkler Sözlüğü adlı eserinde bunu doğrulamaktadır. Fransızcada turkuazın bir diğer anlamı ise "Türk'e mahsus" demektir (Aktaran: Karakulak, 2015: 85). C.Gustav Jung (2007: 232), Insan ve Sembolleri adlı kitabında ise sembolizmin tarihi her şeyin, doğal nesnelerin (taşların, bitkilerin, hayvanların, insanların, dağlar ve vadilerin, güneş ve ayın, rüzgar, su ve ateşin) ya da insan eliyle yapılmış olanların (ev, tekne ya da arabaların), hatta soyut biçimlerin (sayıların ya da üçgen, dörtgen ve dairelerin) simgesel anlam kazanabileceğini gösterdiğini yazar. Gerçekte bütün evrenin potansiyel bir simge olduğundan söz eder. Türk el sanatları içinde yer alan nazar boncuğunun sembolik anlamlarının izi sürüldüğünde, Türk halk kültüründe mavi renginin anlamları şu şekildedir: Öncelikle Çinlilerde, Ön ve Orta Asya Türklerinde ve Anadolu'da mavi, "Doğu" yönünü temsil etmektedir. Anadolu'da Büyük Selçuklular'dan kalma Doğu'ya bakan pencereleri mavi olan kümbetler bulunmaktadır. Dikkat edilecek olursa Doğu'da kalan göller, ırmaklar "gök", "mavi”, "gökçe" gibi isimlerle adlandırılmıştır (Gökçe Deresi, Göksu Deresi, Gök Irmak, Gök Çay vb.). Erzincan Kemah’ta bulunan Mengücek Gazi Kümbeti’nin doğu pencereleri mavidir. Güneş doğudan yükseldiği için doğu en kutsal yöndür. Türkler, cennetin de doğuda bulunduğuna inanırlar. Canan Parla bir çalışmasında Mengücek Gazi Kümbeti'ni iç ve dış mimarisiyle, duvardaki süslemeleriyle, içerde bulunan tüm obje ve şekilleriyle, pencereleriyle kısaca tüm detaylarıyla tek tek inceleyip açıklamıştır. Eser, Türklerin İslâmiyet'e geçtikten sonraki yıllarda yaklaşık 1100'lerde yapılmış olmasına rağmen, İslamiyet öncesi Türk kültürünün sembolik öğelerini üzerinde taşımaktadır. Bununla ilgili olarak şunları yazmıştır:6

6 Mengücek Gazi, 1071 Malazgirt Savaşı'na da katılan Büyük Selçuklu emirlerindendir. 1072-1074 tarihleri arasında Erzincan ve Kemah'ta Mengücek Beyliği'ni kurmuştur. 

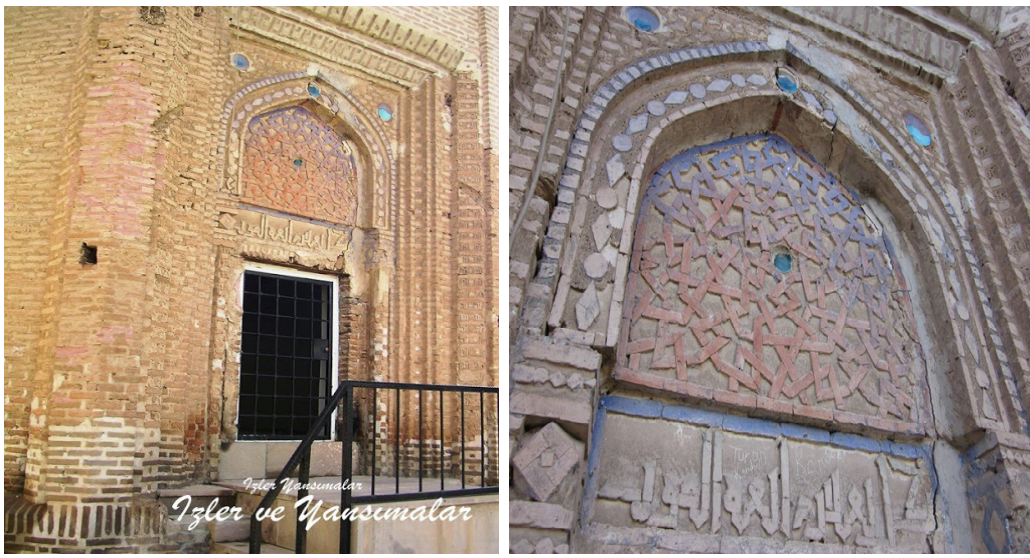

Foto (1-2): Melik Mengücek Gazi'nin Erzincan Kemah’ta bulunan kümbetinin doğu pencereleri mavidir.?

Kümbetin başka penceresinin bulunmayışı, Gök Kapısı'nı simgeleyen bu pencerenin, bilinçli olarak gök kubbeyi simgeleyen tonozun başlangıcına ve Kuzeybatı'ya inşa edildiğini göstermektedir. Cenazelik ve mescit mekânların kapılarının doğu yönünde bulunması, kümbeti sembolik olarak cennet ile ilişkilendirerek bir anlamda cennete açmaktadır. Mescit mekânının duvarına, Mengücek Gazi'nin ilâhi nazarla gözetildiğinin yazılması ve Allah'tan onu, cennetinde iskân etmesinin istenmesi de, Gök Türk kitabelerindeki metinlerin içeriğiyle uyumludur (Parla, 2012: 284).

Anadolu'da henüz yıkılmamış sağlam kalan benzer şekilde doğu yönü pencerelerinin bulunduğu bir başka kümbet de Tokat iline bağlı Niksar'da bulunan Kırk Kızlar kümbetidir. Mavinin halk kültüründe bir başka anlamı ise "yastır" ki bu anlam yukarıda açıklandığı gibi Batı kültüründe de mevcuttur. Neredeyse tüm Türk dünyasında cenaze törenlerinde kadınlar başlarına mavi yazmalar, bellerine mavi kuşaklar sarmaktadırlar. Küçük, Seyidov'dan aktardığı makalesinde Azerbaycan hikâyelerinde gök rengin kederin, matemin belirtisi olduğundan söz etmektedir. Azerbaycan'ın Cebrayıl, Sabirabad, Ağdaş, Gence gibi bölge ve şehirlerinde tabutun üstüne gök ve kara örtülmesi geleneği bugün de devam ettiğini belirtmektedir (Seyidov 1988: 36'dan aktaran: Küçük, 2010: 193).

Dede Korkut hikâyelerinde de yas elbisesi olarak hem siyah hem de mavi-göy (gök) renkli giysilerin giyildiği yazmaktadır. Yas törenlerindeki elbiselerde mavi rengin tercih edilmesi Tanrı'nın gökte kabul edilmesinden, mavinin Tanrı'yı temsil etmesinden kaynaklanmaktadır. Mavinin tercih edilmesiyle mutlak, ilahî olana boyun eğilmekte, Tanrının isteği olgunluk gösterilerek kabul edilmiş olunmaktadır (Kalafat, 2012: 132). ${ }^{8}$

7 Kaynak: https://www.facebook.com/459957280842078/photos/pcb.480905152080624/480904915413981/?t ype=3\&thear, http://izlerveyansimalar.blogspot.com/2009/08/sultan-melik-turbesi.html

8 "Renk Üzerine Denemeler" adlı çalışmasında Özdemir İnce mavi için şunları yazmıştır: "... Ya mavi gömlekli bir dostla gezme, Yahut evine çivit rengi sür! ..." Mavi renk eskiden yas simgesiymiş, "mavi gömlekli dost” yaslı dost anlamına geliyor. Onunla gezmek için ona uymak gerekiyor. "Eve çivit rengi sürmenin" de böyle bir anlamı var. İçinden cenaze çıkan evin kapısına, mavi boya çekermiş eski Türkler (İnce, 2008: 24) 
Türk halk kültüründe mavinin bir başka anlamı ise ululuk, yücelik, kutsallık ve hatta tanrı anlamıdır.Türklerin bilinen en eski inanç sistemlerinden biri de "Gök Tanrı" inancıdır. Bu inanç semavidir. Yani Gök Tanrı'nın şekli şemali, biçimi yoktur. Yabancı ve Türkçe kaynakların kayıtlarına göre, "Gök Tanrı" sözü, tarihin belirli bir döneminde (Hunlar ve Göktürkler) hem maddi gökyüzünü, hem de evrenin yaratıcısı ulu bir varlığı ifade eden kavram olarak kullanılmıştır. Eski çağlarda, her topluluk yaratıcı ulu varlığı, hayatlarında rol oynayan ve etkili olan yerlerde ve varlıklar arasında aramıştır. Bilindiği gibi, Orta Asya'da hayatı en çok etkileyen unsur, yaşamaya son derece elverişsiz olan tabiat ve iklim şartlarıdır. Orta Asya'nın tabiat ve iklim şartları, Türk hayat tarzının, Türk karakter yapısının, Türk örf ve adetlerinin, Türk sanat anlayışının, Türk dünya görüşünün ve daha önemlisi Türk inancının oluşmasında ve şekillenmesinde önemli bir rol oynamıştır (Koca, 2003: 176).

Gökyüzünden gelen ya da orda bulunan yağmur, kar, rüzgâr, fırtına, yıldırım, şimşek, güneş, ay, yıldız vb. doğa olayları hayvancılıkla uğraşan ve göçebe olan Türk toplumunu yakından ilgilendirmiş, dolayısıyla gökyüzüne büyük güçler, anlamlar atfetmişlerdir. Göktürk Yazıtlarında, "gökyüzü" ile "Tanrı" kavramları için aynı kelime, yani "Kök Tengri” kelimesi kullanılmıştır. Bu durum ise, birçok araştırmacının yanılmasına yol açmıştır. Göktürklerde yaratıcı olan varlık ile gökyüzü kavramlarının birbirinden farklı anlamlarda kullanıldığını aynı yazıtlardaki "Tengri teg Tengri” (Tanrı gibi gökyüzü) ifadesinden de anlamak mümkündür (Koca, 2003: 177).

Oğuz Kağan destanında mavi (gök) renk sıkça görülür. Mitolojiye göre Oğuz Kağan gök yüzlüdür. Birinci eşi gökten bir gök ışık içerisinde inmiş, ikinci eşine ise bir ağacın kavuğunda rastlamış ve kızın gözleri gökten daha göktür (mavidir). Oğuz Kağan tarihsel değil, mitolojik bir kişiliktir. Bu kişilikle, o devrin insiyatik eğitiminden geçen bir adayın yaşadıkları ve edindiği bilgiler anlatılmaktadır.

Gök mavisiydi sanki, benzi oğlancığın / Ağzı kıpkızıl ateş rengi bu oğlancığın

Yüz, eski Türklere göre insanın en önemli organdır. Utanç, kötülük, iyilik ve hatta kutsallık bile insanın yüzüne akseden özelliklerdi. Bu sebeple kötülerin yüzü "kara”, iyilerin yüzü "ak", kutsal insanların yüz rengi ise "gök mavisi" olarak mitolojide sembolleştirilmiştir (Candan, 2017: 38). Mitolojiye göre; Tan yeri ağarınca Oğuz Kağan'ın çadırına güneş gibi bir ışık girer ve bu ışıktan gök tüylü, gök yeleli büyük bir erkek kurt (kök tülüklüg kök çallug bedik bir irkek böri, yılkı yallı gök bürü) çıkar. Gök kurt Tanrı'nın alâmet ve habercisi, kurtarıcı (Oğuz ve Kıpçaklarda), ata (Çiğil, Yağma, Karluk boylarında), koruyucu olarak askerin önünde yürür ve yol gösterir. (Küçük; 2010: 188). "Türkçede boz renk, Avrupalıların gri rengine karşılıktır. Gri rengin ise koyudan açığa doğru pek çok tonları vardır. Moğolca metni tercüme eden Çinli yazar, bu kurdun rengi için "Gök renginde kurt' demiştir. Bu renk daha ziyade mavi-gri bir renktir." (Ögel 1998: 575).

Moğol ve Türk boylarındaki efsanelerde mavi kurt ve mavi aslan önemli bir yer tutar. Moğol ve Türk mitolojisinde mavi aslan ve kaplanlar, Altay boyunun atası sayılan Tengri'nin gücünü sembolize eder. Tengri Altaylarda dağların üzerindeki mavi göklerin, mutlak hakîmiyetin sembolüdür (aktaran, Mazlum, 2011:133). Ünlü tarihçi Mircea 
Eliade'nin de vurguladığı gibi Tengri sözcüğüne ulu gök tanrı olarak M.Ö. 2. yüzyılda Hiung-nu'larda rastlanır. Metinler onu "ulu" (üze), "ak ve göksel" (mavi), ezeli ve ebedi (mengü) olarak tanıtır. Yani Kök Tengri, Mavi Gök anlamına gelmektedir (aktaran, Albayrak, 2010: 49).

Türkçede "gök" kelimesi hem "mavi" hem de "yüce/üstün/yüksek" anlamlarını içermektedir. Dolayısıyla Gök Tanrı yücelerde, göklerde bulunan bir varlık olarak algılanabileceği gibi renginin de mavi olması muhtemeldir (Albayrak, 2010: 50). Kısaca Türkler, İslamiyet öncesinde Gök Tanrı inancını benimsemiştir. Hunlar, Tabgaçlar, Göktürkler, Uygurlar gibi Asya'nın doğu ucundan Orta Avrupa'ya kadar her yerde kendini gösteren tarihi Türk topluluklarında yüce bir Tanrı'nın varlığına ve onun da gökte olduğuna inanmışlardır. Eski Türk devletlerinin ve şimdiki bazı Türki Cumhuriyetlerin bayrakları turkuaz rengindedir.

Mavinin anlamlarından bir diğeri ise nazar değmesini engellemesi ve nazardan korumasıdır. Türkler bunu da mavi renkli bir göz boncuğu olan "nazar boncuğu" ile kırmaya, yani engellemeye çalışmaktadırlar. Nazar, Türk halkının geleneksel inanç boyutunu oluşturmaktadır. Ergün Candan Türklerin Kültür Kökenleri adlı kitabında nazar anlayışından şu şekilde söz etmektedir: Günlük yaşantımıza kadar giren ve Anadolu halk geleneklerinde yer alan bu inanç; kimimiz için batıl itikat, kimimiz için ise gerçekliği kabul edilmiş bir olgudur. Ancak şurası bir gerçek ki temeli binlerce yıl öncesine dayanan bu inanç, günümüzde de yaygın bir şekilde varlığını sürdürmektedir. Yaşamımız boyunca, sürekli olarak çevremize kendi düşüncelerimiz sonucu ortaya çıkan birtakım enerjiler yollarız. Nazar dediğimiz şey negatif bir düşünce enerjisiyle karşılaşmak demektir. Nazar inancının ortaya çıkışının temelinde de bu vardır. İster negatif, ister pozitif yüklü olsun düşünce enerjileri, alın ve gözlerden yayıldıkları için "nazar" inancında gözlere büyük bir önem verilmiştir (Candan, 2017: 424). Eski Mısır'da "Osiris'in Gözü" ve "Horus'un Gözü" diye bilinen bazı ezoterik semboller de nazarlık olarak kullanılmıştır. Bu sembollerin de negatif etkileri uzaklaştırdığına inanılırdı (Candan, 2017: 424).

Türk Dil Kurumu Sözlüğü'nde nazar şu şekilde açıklanmıştır: (isim) Belli kimselerde bulunduğuna inanılan, kıskançlık veya hayranlıkla bakıldığında insanlara, eve, mala mülke hatta cansız nesnelere kötülük verdiğine inanılan uğursuzluk, göz . Boratav da nazarı, bakışlarında zararlı güç bulunan bazı insanların bu özellikleriyle bir kişiye, bir hayvana ya da bir nesneye bakmakla canlı üzerinde hastalık, sakatlık, hatta ölüm; nesne üzerinde sakatlanma, kırılma gibi olumsuz bir etkinin meydana gelmesi şeklinde açıklamıştır (Boratav, 1997:103-104).Türk halk kültüründe nazar, sadece kötü ve kıskanç bakışlardan değil aynı zamanda aşırı sevgiden de kaynaklanabilir. Nitekim, "Insana sevdiğinin nazarı daha çok değer" sözü, halk arasında yaygın olarak kullanılan bir sözdür. Hatta annelerin aşırı sevgiden çocuklarına nazar değdirdiğine bile inanılır. Çok eski çağlardan bu yana insanoğlu, cevabını bulamadığı hastalıklarını, rahatsızlıklarını nazarla açıklamaya çalışmıştır. İnsanların ilişkileri bozulursa, bebek hastalanırsa, bol süt veren ineğin sütü kesilirse sebebi hep nazardır ve bu durumlar 
karşısında "nazar değdi" denir.Halkbilimci Orhan Acıpayamlı, nazarın genellikle mavi gözlü ve sarı saçlı bir kimsenin, diğer bir kimseye, hayvana veya eşyaya kötü gözle bakması ya da bunlar hakkında methedici sözler söylenmesi ile meydana geldiğinden bahseder. Nazar değdiğinde de o insan ya da hayvan hastalanır veya ölür. Eşya ise kırılır, dökülür, yıkılır veya yanar. Özellikle "bakmak" ve "söylemek" işlemlerinin kötülüklere iletken görevi oluşturduğunu belirtmekte ve bu açıklamasını da şu şekilde formüle etmektedir: (Acıpayamlı, 1962: 15).

(bakmak x söylemek) $x$ insan (hayvan, eşya) $=>$ hastalık, ölüm.

Acıpayamlı (1962:16), neden Türk halkının sarı saçlı, mavi gözlü, keskin dilli insanların nazar değdireceğine inandığını da sorgulamış ve şu yanıtlamaktadır: "Cemiyetimiz, esas olarak, siyah ve kestane saçlı, beyaz ve esmer tenli fertlerden meydana gelmiştir. Böyle bir topluluk, düşman olarak çok defa mavi gözlü ve sarı saçlılarla karşılaşmıştır. Halk arasında gezenler mavi göz ile sarı saçın pek tutulmadığını görmüşlerdir. Bu his, geçmiş zamanlarda daha da köklü idi. Bu sebeple halk, öldürücü kudrete sarı saçlılık ve mavi gözlülük sıfatlarını vermekte gecikmemiştir".

Böylece kişi mavi gözü andıran nazar boncuğunu takarak nazar değdireceğinden korktuğu mavi gözlülere "göze karşı gözle" korunmakta öte yandan da Gök Tanrı'nın gözü gibi düşünüldüğünde ise bu sembolik küçük mavi göz boncuğunun kendisini nazarlardan koruduğuna inanmaktadır. Kısaca Türk halkı nazardan korusun diye de nazar değdiğine (nazara geldiğine) inandıktan sonra da her iki halde de nazar boncuğunu kullanmıştır ve kullanmaktadır.

Peki, nazar boncuğu neden mavidir? Zanaatkâr, boncuğu aynı formda ama istediği farklı bir renkte elbette ki üretebilir ki üretmektedir de. Bunları turistik beldelerde görmekteyiz. Ancak pembe veya yeşil bir nazar boncuğunun anlamı (nazar kırıcı anlamında) mavi gibi olmamaktadır. Nazar boncuğu denildiği zaman akla mavi/turkuaz mavisi gelmektedir.

Önder Küçükerman, kitaplarında nazar boncukçuluğunun nasıl yapıldığına dair teknik boyutu derinlemesine incelemiştir: Buna göre nazar (göz) boncukçuluğu M.Ö. 3000'lere dayanan bir el sanatı dalıdır. Doğu Akdeniz, Mısır, Mezopotamya, Suriye, İran ve Anadolu kısacası denizin, kumun ve çam ağacının olduğu yerde bu sanat varlığını sürdürmüştür. Binlerce yıldan beridir yaşayan bu cam sanatında kullanılan malzeme, araç, gereç, yöntem neredeyse hiç değişmemiştir.

Tarihin çeşitli dönemlerinden cam boncukçuluğunun tarifini veren, çivi yazısıyla yazıımış tabletler bulunmuştur. İngiliz araştırmacı S. Goodfield Toulmin'in The Architecture of Matteradlı kitabından Küçükerman şöyle aktarıyor: Örneğin Bağdat yakınlarında M.Ö. 1690-1696 "Gülkishar" döneminden kalma ve 1000 yıl sonra da Asur kralı Asurbanipal zamanından kalma tabletlerde cam ustalarının anlatımı vardır. Hatta kullanılan dil "böyle yap, sonuç şöyle olacaktır” tarzındadır (Toulmin, 1968:30'dan aktaran; Küçükerman, 1987: 18-19). Tarihin her döneminde pahalı ve gerçek bir "değerli taş" yerine "aynı görüntüyü" sağlayan ucuz bir "yapay taş” geniş bir kullanıcı kesimi için her zaman çok çekici olmuştur (Toulmin, 1968:31'den aktaran; Küçükerman, 1987: 20). 
Genel olarak camcılık kimyasal bir işlemdir. Doğada "cam" adında bir maden yoktur. Cam bir "yapı düzeninin" adıdır. Camsı durum, katı, sıvı, gaz ve plazma gibi maddenin durumlarından biridir. Çoğu madenlerin atomları katı durumdayken sabittir, ısıtıldıkça hareketlenirler. Belirli bir sıcaklıkta atomlar birbirinden ayrılır buna "erime" denir. Eritilmiş sıvılar yavaşça soğutulursa madde yavaş yavaş eski haline gelir. Eğer soğuma çok hızlı bir biçimde gerçekleşirse düzensiz halleri ile katılaşır. Bu tür katılara da "cam" denir (Küçükerman, 1987: 76). Ocaklarda kullanılan toprak fırınlar, sürekli ısınıp soğuduğu için, bir süre sonra çatlamakta ve cam ustaları her sene toprak fırınları yeniden yapmaktadırlar.

Cam boncuklar "sarma yöntemi" ile yapılır. Son derece akıcı olan erimiş cam, çubuğu potanın içine sokup döndürünce ucuna sarılıp yapışıverir. Cam biçimlendirilmede ilk işlem, camı bir çubuğa sararak potadan almaktır (Küçükerman, 1987: 69). Göz boncuğu üreten ocaklarda en çok mavi renk kullanılır. Çünkü mavi renk, ısı değişimlerinden fazla etkilenmez. Buna karşılık sarı, turuncu, beyaz daha zor ve bir anlamda daha pahalı renklerdir. O nedenle, boncuklar genellikle mavidir (Küçükerman; 1985: 199)

Kobalt oksit $(\mathrm{CoO})$ cama mavi rengini verir. Dış görünüşü simsiyahtır, ama buna rağmen her şart ve ortamda (farklı ısılarda, farklı oksijen miktarı altında, farklı soğuma ısılarında) cam hep mavi olur. Mavi rengi veren bir diğer madde ise bakır oksittir (CuO). Kobalt fiyat olarak bakırdan çok daha pahalıdır. Ama kobaltın yaklaşık olarak 10 katı kadar bakır, benzer maviyi ve koyuluğu verir. Bakır, Anadolu'da çokça bulunur (Küçükerman, 1987:80-81). Mezopotamya'dan Mısır'a, Doğu Akdeniz'den Anadolu'ya kadar pek çok yerde, ilk camcılık örnekleriyle karşılaşmak mümkündür. İlk örnekler M.Ö. 3000'lerden kalmadır. Bunlar "mücevhersi” görünümleriyle dikkat çeken taş ve pişmiş toprak boncukların camsı boncuklar biçimine dönüştürülmüş örnekleridir (Küçükerman, 1985: 31-34).

Mavi, cam sanatında en kolay elde edilen renktir. Bu durum cam sanatlarının gelişmesi için bir şans olarak kabul edilebilir. Şanstır çünkü mavi renk aynı zamanda Türk kültüründe "Gök Tanrı" inancından bu yana kutsal sayılmaktadır. Çünkü diğer renklere göre doğadaki cam kolaylıkla kendi kendine maviye dönüşmektedir. Bu kesinlikle kimyasal bir süreçtir. Ancak Türk halkının mavi rengi ne kadar önemsediği göz önünde bulundurulduğunda mavinin boncukla özdeşleşmesi kültürel süreklilik açısından da inanılmaz bir etkendir.

\section{Sonuç}

$\mathrm{Bu}$ tarihsel nitel analizde mavi ve turkuaz mavisinin sembolik olarak anlamı ve Türk kültüründeki yeri "nazar boncuğu" inancı üzerinden açıklanmaya çalışılmıştır. Öncelikle Batı kültüründe mavinin tarihsel süreç içerisinde değişen anlamları, daha sonra da Türk kültüründeki anlamları ortaya konulmuştur. Batı’da 12. yüzyıla kadar mavi adeta hiç sevilmeyen ve korkulan bir renktir. Mavi Avrupalılarca barbarların rengi 
olarak görüldüğünden Batılılar bu renge rağbet etmemişlerdir. 12.yüzyıldan sonra mavi, Meryem Ana'yı temsil eden renk olmuştur. Din sembolizminde artık Meryem Ana'nın, oğlu İsa'nın yasını tutan bir anne olarak mantosu, elbisesi maviyle boyanarak resimlere konu olmuştur. Mavi Avrupa ülkelerinde zamanla üniformaların rengi olmuş ve 20. yüzyılda popüler kültür ürünü olan kot pantolonlarla en sevilen renk olmayı başarmış. Renk sembolizminde özellikle soyut sanatta, mavi hüzün, tinsel derinlik, sonsuzluk, özgürlük ve barış anlamlarını da almıştır.

Türk halkı için ise mavi, binlerce yıldan bu yana hep kutsallık, yücelik ve Tanrı anlamındadır. Öyle ki mavi, gökyüzü ve Tanrı demek hep aynı, "gök" kelimesiyle ifade edilmiştir. İslâmiyet öncesi Türklerin inandıkları "Gök Tanrı" inancı ile mavi rengi hep kutsanmıştır. Hatta yücelerde, göklerde bulunan bir varlık olarak algılanan Gök Tanrı'nın renginin de mavi olduğu düşünülmüştür. Türk mitolojisinde Gök Tanrı'nın yeryüzüne Türk toplumunun başına getirdiğine inandıkları hakanlar hakkında söylenen mitoloji ve destanlarda da ön plâna mavi yeleli bir kurt çıkar: Boz Kurt. Yanı sıra, Doğu yönü de yine mavi renk ile adlandırımış (Doğu; gök, Batı; ak, Kuzey; kara, Güney kızıl), güneş doğudan doğduğu için cennetin de doğuda olduğuna inanılmış ve sembolü de hep mavi olmuştur. Türklerde yas, mavi ile kendini göstermiş ve nihayetinde nazar inancına dayanan ve ondan korunma yollarından biri olan nazar boncuğunun da mavisi kabul görmüştür. Batılıların nefret ettiği, korktuğu, küçümsediği bu renk, Türkler için kutsaldır. Binlerce yıldır da Türk halkı bu renge ve nazar boncuğuna verdirdikleri önemi sürdürmektedir.

Nazar, Türk kültüründe ve inançlarında nesiller boyu önemli bir olgudur. Nazar inancı ve onu engelleme yolları kimilerine göre hurafe, batıl veya akıl dışı kabul edilse de en az 5000 yıldır sürdürülen kültürel bir olgu olduğu açıktır. Öyle ki Türk halkı 21. yüzyılda sosyal medyada ilişkilerine, bebeklerine, çocuklarına, sevdiklerine nazar değmesin diye fotoğrafların altına nazar boncuğu resmi dahi etiketlemektedirler.

Geleneksel halk kültürünün bir parçası olan renk sembolizmi, İslam öncesi, İslam ve Batı medeniyetleri ile etkileşerek tarihsel süreçlerden geçerek oluşmuştur ve içinden çıktığı tarihsel ve toplumsal koşulların bir yansımasıdır. Osmanlı-Türk toplumu son 200 yılda çok hızı bir Batılaşma süreci yaşamasına rağmen, mavi renk, nazar ve nazar boncuğunun kötülüklerden koruyucu etkisine yönelik popüler inanç ve değerlendirmeler, değişen koşullara uyarak varlığını sürdürmüştür. Yaşanan değişmelerle ne tam anlamılla geleneksel ne de tam anlamıyla modern olamayan, kendine özgü, geleneksel ile modern arasına sıkışmış melez bir kültürel yapı oluşmuştur. Bu yapı içerisinde geleneksel inanç ve değerlerin halkın belirli bir kesiminin popüler bilincinde varlığını koruduğu ve sürdürdüğü görülmektedir. Yaşanan modernleşme süreçlerine karşın geleneksel değer, inanç ve eylemlerin kültürel mantık ve ilkelerini değiştirmediği söylenebilir. Osmanlı-Türk toplumu gibi kendi içsel dinamikleriyle değil de dışsal etki ve yönlendirmelerle yapılan Batılaşma çabalarında radikal bir kültürel kopuştan ziyade kültürel bir süreklilik olduğu görülmektedir. 
ekonomik sistemler, eğitim, aile yapısı ve cinsiyet ilişkileri gibi toplumsal reformlarda somutlaşmaktadır. Özellikle geleneksel toplumsal zihniyet açısından keskin bir kırılma değil, kültürel sürekliliğe bağlı olarak uzun bir geleneğin bulunduğu yadsınamaz. İlk uygarlıklar aşamasında, bugünkü insanların ataları tarafından oluşturulan gelenekler toplumsal hafızada, insanların duygu, düşünce ve his yapılarında varlığını sürdürmektedir.

Burada kültür en geniş anlamıyla belli bir toplumsal, tarihsel formasyonda yaşayan insanları birbirinden ayıran kalıcı bir düşünce, inanç, eylem, gelenek ve kurumsal yapılandırmayı dile getirmektedir. Değişken bir olgu olan kültürel örüntüler bir yönüyle kalıcı, bir yönüyle de değişime açık çelişkili diyalektik süreçler ve bütünlüklerdir. Mavi renk ve nazar boncuğu konusunda olduğu gibi geleneksel, değer inanç ve davranışlar, yüksek kültür ve bilimsel alandaki gelişmelere karşın varlığını sürdürmektedir. Kültürel değişmelerin tarihsel ve toplumsal değişmeleri bağlı olduğu ve onları aşamayacağı belirtilmelidir. Tarihsel ve toplumsal değişme hızı, Batı dışı toplumlarda farklıdır. Tarihsel ve toplumsal kopuşların yaşanmadığı süreçlerde kültürel sürekliliğin daha belirgin olacağı beklenebilir. Bu açıdan Osmanlı-Türk tarihinde dış etkenlerle yaşanan toplumsal reformlar toplumsal zihniyet açısından bir kopuş getirmemiş, Türk halkına özgü tarihsel süreç içerisinde oluşmuş manevi nitelikler ve kişilik özellikleri varlığını, nazar inancı gibi popüler inançta varlığını devam etmektedir.

\section{Kaynakça}

ACIPAYAMLI, Orhan (1962), Anadolu'da Nazarla İlgili Bazı Âdet ve İnanmalar, Ankara Üniversitesi Dil ve Tarih Coğrafya Fakültesi Dergisi, Cilt XX-Sayı: 1-2 Ocak-Haziran. ss. 1-40.

ADALAR SUBAŞı, Derya, (2012). Renkler Ulamı Üzerine Türkçe ve Arapça Sözlük Tabanına Yönelik Gözlemler, Turkish Studies, International Periodical for the Languages, Literature and History of Turkish or Turkic, Volume 7/2 Spring , Ankara, ss.963-977.

ADORNO, Theodor W. (2003). "Kültür Endüstrisini Yeniden Düşünürken”. Çev.: Bülent O. Doğan. Cogito. Sayı: 36. Yaz. Ss.: 76-83.

AKŞiN, Sina (1997). "Düşünce Tarihi (1945 Sonrası)". Türkiye Tarihi 5:Bugünkü Türkiye (19801995) (içinde). Der: Bülent Tanör, Korkut Boratav, Sina Akşin. 2. Basım. İstanbul: Cem.

AKTAR, Cengiz (1993). Türkiye'nin Batıılaştıtılıması. İstanbul: Ayrıntı.

Atabek Reşat, "Renk Sembolizmi”, Mimar Sinan Dergisi, 1983, Sayı:48, ss: 33-46.

BARKER, Chris (1999). Television, Globalization, and Cultural Identities. Philedelphia: Open University Press.

BERKES, Niyazi (2006). Türkiye'de Çağdaşlaşma. Yayına Hazırlayan: Ahmet Kuyaş. İstanbul: Yapı Kredi Yayınları.

BERKES, Niyazi (1975). Türk Düşününde Batı Sorunu. İstanbul: Bilgi.

BORATAV, Pertev Naili (1997). 100 Soruda Türk Folkloru. 4.Baskı. İstanbul: Gerçek.

CANDAN, Ergun (2017). Türkler'in Kültür Kökenleri, İstanbul: Sınır Ötesi Yayınları. 
ÇIBLAK, Nilgün (2004). "Halk Kültüründe Nazar, Nazarlık İnancı ve Bunlara Bağlı Uygulamalar”. Türklük Bilimi Araştırmaları. 2004/15. ss:103-125.

DOĞAN, Ahmet (2002). “íslâmiyet’ten Önceki Türk İnancına Dair”. Türkler. Ed. Hasan Celâl Güzel vd. İstanbul: Yeni Türkiye Yayınları. ss.305-319.

ELIADE, Mircea (2018). İmgeler ve Simgeler, Çev: Mehmet Ali Kılıçbay, Ankara: Doğu Batı

EMiNOĞLU, Hatice (2014). Türkçe’de Renkler Sözlügü. Ankara: Gazi Kitabevi.

ER Mine (2005). Elazığ’da Nazarla IIlgili İşlemlerin Sosyolojik Tetkiki. Elazığ: Fırat Üniversitesi Sosyal Bilimler Enstitüsü, Yayınlanmamış Yüksek Lisans Tezi.

ERDOĞAN, İrfan (2002). İletişimi Anlamak. Ankara: Erk.

ERDOĞAN, İrfan (2001). "Popüler Kültürde Gasp ve Popülerin Gayrimeşruluğu". Doğu-Batı. Yıl:4. Sayı: 15. Mayıs-Haziran-Temmuz. Ss.:65-102.

FINLAY, Victoria (2007). Renkler Boya Kutusuna Yolculuklar. Çev: Kudret Emiroğlu. Ankara: Dost Kitabevi.

FISKE, John (1999). Popüler Kültürü Anlamak, Çev: Süleyman İrvan, Ankara:Ark.

GALLAND, Oliver ve LEMEL, Yannick (2008). "Tradition vs Modernity: The Continuing Dichotomy of Values in European Society". Revue Françoise de Sociologie. Vol.: 49. No: 5. 153-189.

GIDDENS, Anthony (1990). The Consequences of Modernity. Cambridge: Polity Press.

GÜVENÇ, Bozkurt (1991). İnsan ve Kültür. 5. Baskı. İstanbul: Remzi Kitabevi.

GÜVENÇ, Bozkurt (1985). Kültür Konusu ve Sorunlarımız. 2. Baskı. İstanbul: Remzi Kitabevi.

HUNTINGTON, Samuel P. (2008). Medeniyetler Çatışması ve Dünya Düzeninin Yeniden Kurulması. Çev.: Mehmet Turhan ve Y. Z. Cem Soydemir. VI. Baskı. İstanbul: Okuyan Us.

INGLEHART, Ronald ve BAKER, Wayne (2000). "Modernization, Cultural Change, and the Persistence of Traditional Values". ASR 2000. Vol: 65 No: 1. Pp. 19-51.

iNCE Özdemir, "Renkler Üzerine Denemeler", Renkler, Simge Kültür ve Edebiyat Seçkisi, Temmuz-Ağustos 2008, Sayı: 36: 24.

JUNG, C. Gustav, İnsan ve Sembolleri, (2007). Çev: Ali Nahit Babaoğlu, İstanbul: Okuyan Us.

KALAFAT, Yaşar (2012). Türk Halk Inançlarında Renkler, Ankara: Berikan Yayınevi.

KARTARI, Asker (2001). Farklılıklarla Yaşamak Kültürlerarası IIletişim. Ankara: Ürün Yayınları.

KOCA, Salim, (2003). Türk Kültürünün Temelleri II. Ankara: Berikan Yayınları.

KONGAR, Emre (1997). Kültür Üzerine. 5. Basım. İstanbul: Remzi Kitabevi.

KORKMAZ, Nilufer (2008). "Kültürel İncelemeler Geleneğinde "Kültür, Popüler Kültür ve İdeoloji" Sorunu”. Medya, Popüler Kültür ve İdeoloji (içinde). Der.: L. Yaylagül, N. Korkmaz. Ankara: Dipnot. 
KONGAR, Emre (1995). Toplumsal Değişme Kuramları ve Türkiye Gerçeği. 6. Basım. İstanbul: Remzi Kitabevi.

KOTTAK, Conrad Philip (2002). Antropoloji: Insan Çeşitliliğine Bir Bakış. Çev.: Serpil N. Altuntek, Balkı Aydın Şafak, Dilek Erdal vd. Ankara: Ütopya.

KUYAŞ, Ahmet (2016). Tarihi Düşünmek. İstanbul: Kırmızıkedi Yayınları.

KÜÇÜK, Salim (2010), Eski Türk Kültüründe Renk Kavramı, Bilig, Yaz. Sayı 54: 185-210.

KÜÇÜKERMAN, Önder, (1985), Cam Sanatı ve Geleneksel Türk Camcılığından Örnekler, İstanbul: Türkiye İş Bankası Yayınları.

KÜÇÜKERMAN, Önder, (1987), 3000 Yıllık Akdeniz Camcıığının Anadolu'daki Son İzleri Göz Boncuğu, İstanbul: Türkiye Turing ve Otomobil Kurumu Yayını.

MALINOWSKI, Bronislaw (1990). İnsan ve Kültür. Çev.: M. Fatih Gümüş. Ankara: Verso Yayınları.

MAZLUM, Özge, (2011). Rengin Kültürel Çağrışımları, Dumlupınar Üniversitesi Sosyal Bilimler Dergisi, Sayı:31, ss: 125-138.

MEJUYEV, Vadim (1998). Kültür ve Tarih. Çev.: Suat H. Yokova. 2. Baskı. İstanbul: Toplumsal Düşünceler.

MODELSKI, Tania (Ed.) (1986). Studies in Entertainment: Critical Approaches to Mass Culture. Bloomington and Indianapolis: Indiana University Press.

MUTLU, Erol (2001). "Popüler Kültürü Eleştirmek". Doğu-Batı. Yıl:4. Sayı:15. Mayıs-HaziranTemmuz. ss: 9-39.

OKTAY, Ahmet (1997). Türkiye'de Popüler Kültür. 4. Baskı. İstanbul: Yapı Kredi Yayınları.

O'SHAUGHNESSY, Michael (1995). "Box Pop: Popular Television and Hegemony". (in) Understanding Television. Eds.: Andrew Goodwin and Whannel, Garry. 4th Editiın. New York: Routledge. Pp. 88-102.

ÖGEL, Bahaeddin (1998). Türk Mitolojisi. Ankara: Türk Tarih Kurumu Yayını.

ÖNDiN, N. (2008). Nesnenin Çözünülürlüğü: Kandinsky-Mondrian ve Kırmızı. Sanat Dünyamız Üç aylık kültür ve sanat dergisi, ss.105-113.

PETKOVIC, Jelena (2007). "Traditional Values and Modernization Challenges Informing Urban and Rural Culture". Philosophy, Sociology, and Philosophy. Vol: 6. No:1. Pp.: 23-39.

SPENGLER, Oswald (1973). İnsan ve Teknik. Çev.: Kamil Turan. Ankara: Töre-Devlet Yayınları.

STOREY, John (2000). Popüler Kültür Çalışmaları. Çeviren: Koray Karaşahin. İstanbul: Babil Yayınları.

SUNYER-PI, Oriol ve SALZMAN, Zdenek (1978). Humanity and Culture: An Introduction to Anthropology. Boston: Houghton Mifflin Company.

TANPINAR, Ahmet Hamdi (1996). Yaşadığım Gibi. İstanbul: Dergâh. 
UÇAR, Tevfik Fikret (2004). Görsel Iletişim ve Grafik Tasarım, İstanbul: İnkılap Kitabevi.

WILLIAMS, Raymond (1993). Kültür. Çeviren: Suavi Aydın. Ankara: İmge Yayınevi.

KANDINSKY, Wassily, (2017). Sanatta Tinsellik Üzerine,Çev: Özkan Eroğlu, İstanbul: Tekhne Yayınları.

KARAKULAK Nigar, (2015). Renklerde Adlandırma, Kırklareli Üniversitesi Sosyal Bilimler Enstitüsü Türk Dili ve Edebiyatı Anabilim Dalı Yüksek Lisans Tezi, s. 85.

TDK, http://www.tdk.gov.tr/index.php?option=com_gts\&kelime=NAZAR, /Erişim Tarihi: (27.02.2019)

\section{Fotoğrafların Kaynakçası}

https://www.facebook.com/459957280842078/photos/pcb.480905152080624/48090491541398 1/?type=3\&theater (Erişim Tarihi: 27.02.2019).

http://izlerveyansimalar.blogspot.com/2009/08/sultan-melik-turbesi.html 27.02.2019). 